\title{
ESTRATÉGIAS DE EDUCAÇÃO CORPORATIVA E SUAS RELAÇÕES COM OS D̉IFERENTES NIIVEIS DE APRENDIZAGEM ORGANIZACIONAL
}

\author{
STRATEGIES FOR CORPORATE EDUCATION AND \\ ITS RELATIONS WITH THE DIFFERENT LEVELS OF \\ ORGANIZATIONAL LEARNING
}

Data de submissão: 10-12-2012 Aceite: $17-08-2013$

Ticiana Moscardini ${ }^{1}$

Amarolinda Zanela Klein²

\section{RESUMO}

A Educação Corporativa, como um processo de educação profissional contínua proporcionada pela organização, é um sistema que integra conceitos como Gestão do Conhecimento, Gestão por Competências e Aprendizagem Organizacional. A Aprendizagem Organizacional, por sua vez, é dinâmica e ocorre de modo individual, grupal ou institucional, e sua análise pode ocorrer por meio do framework dos 4 "Is" (Intuição, Interpretação, Integração e Institucionalização), proposto por Crossan, Lane e White (1999). Diante disso, este artigo, de caráter teórico, tem como objetivo analisar a relação entre as Estratégias de Educação Corporativa e o framework proposto por Crossan, Lane e White (1999), identificando de que forma cada estratégia pode perpassar os diferentes níveis de Aprendizagem Organizacional e colaborar com esse processo. Como principal resultado deste trabalho, apresenta-se um framework, que colabora para o entendimento e a discussão da complexidade existente para alcançar, de fato, a aprendizagem em nível organizacional, por meio de diferentes estratégias de educação corporativa. Este novo framework pode ser utilizado, na prática, por gestores ao planejarem ou avaliarem iniciativas de Educação Corporativa, bem como pela academia para a compreensão desse conceito e para a formação de gestores.

Palavras-chave: Educação Corporativa. Estratégias de Educação Corporativa. Aprendizagem Organizacional.

\footnotetext{
${ }^{1}$ Possui graduação em Administração pela Universidade do Vale do Rio dos Sinos - UNISINOS e mestrado em Administração pela Universidade do Vale do Rio dos Sinos - UNISINOS. São Leopoldo. Rio Grande do Sul. Brasil. E:mail: ticimoscardini@gmail.com

${ }^{2}$ Possui graduação em Administração pela Universidade Federal de Santa Maria - UFSM, mestrado em Administração pela Universidade Federal do Rio Grande do Sul - UFRGS e doutorado em Administração pela Universidade de São Paulo - USP. Atualmente é Professora do Programa de Pós-Graduação em Administração da Universidade do Vale do Rio dos Sinos - UNISINOS. São Leopoldo. Rio Grande do Sul. Brasil. E-mail: amaroklein@gmail.com
} 


\section{ABSTRACT}

Corporate Education is a process of continuous professional education provided by the organization, as a system that integrates concepts like Knowledge Management, Competency Management and Organizational Learning. Organizational learning is dynamic and occurs in an individual, collective or institutional level; its analysis can be done with the "4 Is" framework (Intuition, Interpretation, Integration and Institutionalization) proposed by Crossan, Lane e White (1999). This theoretical paper aims to analyze the relationships between Corporate Education strategies of and the framework proposed by Crossan, Lane $e$ White (1999), identifying how each strategy can promote the different levels of organizational learning, collaborating with this process. As the main research result, it was possible to develop a theoretical framework that contributes to the understanding and discussion of the complexity to develop, in fact, learning at the organizational level through different strategies of corporate education. This new framework can be used in practice by managers for planning or evaluating initiatives of Corporate Education, as well as by academia, to explain the concept of corporate education and for management training.

Keywords: Corporate Education. Corporate Education Strategies. Organizational Learning.

\section{INTRODUÇÃO}

Ao analisar as mudanças ocorridas entre o século XX e o século XXI, percebe-se que, no início do século XX, o mundo do trabalho possuía uma relativa estabilidade, que permitia uma separação entre trabalho manual e intelectual. Com o surgimento de um ambiente mercadológico em constantes mudanças, especialmente a partir da segunda metade do século $X X$, houve uma significativa alteração no perfil das equipes e dos gestores, demandando a disseminação mais rápida e eficaz do conhecimento e um maior comprometimento de todos os envolvidos com os objetivos organizacionais (EBOLI, 2004).

A organização do século XXI deve estar atenta a esse cenário, proporcionando ambientes adequados à aprendizagem. Pensando nisso, empresas de excelência estão se comprometendo cada vez mais com o processo de qualificação e educação de suas equipes, por meio de programas estruturados, que visam desenvolver os profissionais de quais a organização necessita para se manter competitiva no mercado (MEISTER, 1999; KROGH; ICHIJO; NONAKA, 2001).

Nesse contexto, surgem as práticas de Educação Corporativa, que favorecem o aprendizado, criando condições para a inovação, o empreendedorismo e o desenvolvimento de líderes eficientes (EBOLI, 2004). A Educação Corporativa consiste, assim, no conjunto de ações educacionais que a empresa estabelece a fim de assegurar que todos os participantes da sua cadeia de valor (funcionários, parceiros, fornecedores e clientes) possam desenvolver as competências profissionais necessárias para a concretização da estratégia organizacional, com foco no negócio (MEISTER, 1999; ANTONINI, 2009). Por vezes, o conceito de Educação Corporativa é confundido com o conceito de Universidade Corporativa. Neste trabalho, eles não serão utilizados como equivalentes, pois, de acordo com o conceito de Educação Corporativa ora adotado (visão estratégica da capacitação e desenvolvimento de pessoas), a Universidade Corporativa é apenas um dos meios para o desenvolvimento de estratégias de Educação Corporativa, como será discutido mais adiante.

Crossan, Lane e White (1999) voltaram-se à compreensão do processo de criação e de disseminação do conhecimento na empresa e, ao estudar a Aprendizagem Organizacional, desenvolveram um framework, o chamado 4 "Is" (Intuição, Interpretação, Integração e Institucionalização), cujo processo ocorre em diferentes níveis da organização, começando pelo indivíduo até chegar à institucionalização. A Aprendizagem Organizacional é um processo dinâmico, não ocorrendo, portanto, de forma pontual em um único nível (CROSSAN; LANE; WHITE, 1999). Ela é trabalhada pela Educação Corporativa, que abrange uma série de estratégias e metodologias (PACHECO et al., 2009). 
Embora a Aprendizagem Organizacional venha recebendo a atenção das organizações e dos estudos acadêmicos nas últimas décadas (BARRETO et al., 2011), poucos modelos teóricos relacionam diretamente as estratégias de Educação Corporativa com os diferentes níveis de Aprendizagem Organizacional, de forma que seja possível avaliar como cada uma dessas estratégias, quando aplicadas na prática, pode colaborar com cada um dos diferentes níveis de aprendizagem no contexto organizacional. A literatura sobre Aprendizagem Organizacional é bastante ampla, porém, muitas vezes, os conceitos a ela relacionados são tratados de forma abstrata, carecendo de ligação direta com práticas de Educação Corporativa que podem ser aplicadas no dia a dia das organizações.

Portanto, o objetivo deste trabalho é analisar as diferentes estratégias de Educação Corporativa à luz do framework de Aprendizagem Organizacional proposto por Crossan, Lane e White (1999), a fim de criar um novo framework de referência para a aplicação dessas estratégias na prática. Esse framework permitirá vincular os dois conceitos (Aprendizagem Organizacional e Educação Corporativa) de forma objetiva, sinalizando suas relações e indicando como diferentes estratégias de Educação Corporativa podem promover a Aprendizagem Organizacional em seus diferentes níveis e subprocessos.

Para isso, este artigo está estruturado da seguinte forma: na sequência, apresenta-se a fundamentação teórica da pesquisa, abordando-se a literatura sobre Aprendizagem Organizacional e Educação Corporativa. Após, é realizada uma discussão, propondo-se um novo framework integrador dos dois conceitos. Por fim, são apresentadas as considerações finais deste artigo, indicando uma série de questões para pesquisas futuras.

\section{EDUCAÇÃO CORPORATIVA}

A consolidação do conceito de Educação Corporativa ocorreu aproximadamente no final da década de 1980 nos Estados Unidos, quando as organizações começaram a perceber que o conhecimento se tornava obsoleto mais rapidamente e que era preciso desenvolver a sua própria força de trabalho, para garantir a competitividade frente ao mercado. Com isso, emergiu a ideia do alinhamento entre o desenvolvimento profissional e as estratégias organizacionais (MEISTER, 1999; EBOLI, 2004; EBOLI et al., 2010; SOKOLOVA, 2011). No Brasil, os estudos sobre Educação Corporativa ainda são escassos, mas grandes empresas já estão trabalhando com este conceito e obtendo resultados significativos (EBOLI et al., 2011).

Meister (1999) define Educação Corporativa como uma estratégia para educar clientes, fornecedores e comunidade, que tem como objetivo alinhar todos os envolvidos para atingir as metas empresariais. A Educação Corporativa deve ser um processo contínuo, e não um ou poucos eventos pontuais, devendo ser previamente planejada por uma série de programas educacionais (MARINELLI, 2007).

Com missão, visão, valores, objetivos e metas claramente definidos, a Educação Corporativa deve ter como norte a estratégia do negócio, permitindo atender às necessidades dos indivíduos e da empresa. É um processo que evoluiu a partir de uma visão tradicional de Treinamento e Desenvolvimento (T\&D), para uma abordagem estratégica de ensino e de aprendizagem, envolvendo atualização constante, o que leva a empresa para o caminho da qualificação corporativa contínua, necessária para a sua sobrevivência e competitividade (PACHECO et al., 2009).

A Educação Corporativa precisa privilegiar programas que proporcionem o aprendizado por meio da ação, fazendo com que o indivíduo aprenda e dê continuidade ao seu processo de desenvolvimento quando aplicar na prática o que aprendeu. Trata-se de uma forma de reestruturar o ambiente de aprendizagem. Portanto, a Educação Corporativa deve ser proativa e centralizada, e as suas iniciativas devem estar atreladas aos indicadores estratégicos da organização (MEISTER, 1999). 
As práticas de Educação Corporativa devem disseminar os valores organizacionais, proporcionando a criação, a aquisição e o compartilhamento do conhecimento e promovendo a aprendizagem, a gestão do conhecimento e, consequentemente, o acesso às informações presentes na empresa, o que representa uma das suas principais forças. O processo ocorre por meio de programas contínuos que envolvem todos os indivíduos no autodesenvolvimento, fortalecendo, dessa forma, as pessoas talentosas e competentes (EBOLI, 2002; SOKOLOVA, 2011; ALAM et al., 2011).

Conforme Eboli (2005), a Educação Corporativa é um sistema integrado e estratégico de educação, calcado na cultura organizacional e baseado na gestão por competências, demandando a participação ativa das lideranças e dos gestores de Recursos Humanos para que sua implementação seja bem-sucedida. Os processos de desenvolvimento de pessoas devem privilegiar a identificação das reais lacunas (gaps) de competências existentes na organização (EBOLI, 2005). Os resultados visam a ganhos de desempenho organizacional e não ao mero acúmulo de horas de treinamento ou certificações profissionais de forma isolada.

O objetivo final da Educação Corporativa consiste, assim, no desenvolvimento das competências organizacionais, que são competências coletivas que resultam da integração e sinergia entre o uso dos diversos recursos e as competências dos indivíduos que compõem a organização. Segundo Le Boterf (2003, p. 229), "a competência de uma empresa ou de suas unidades (divisão, departamento, serviço, oficina) não equivale à soma das competências dos seus membros. Nessa área, o capital não depende tanto de seus elementos constitutivos, mas da qualidade da combinação ou da articulação desses elementos". A Gestão por Competências envolve práticas (por exemplo: de seleção, remuneração e capacitação por competências) que devem ser construídas internamente em cada organização, de acordo com sua cultura e identidade (FLEURY, 2002; BITENCOURT, 2005; BITENCOURT; KLEIN, 2007).

Outro pilar da Educação Corporativa é a Gestão do Conhecimento (KROG et al., 2001), que tem como objetivo proporcionar condições para que os indivíduos possam praticar a sua capacidade de criação, contribuindo, desse modo, para aumentar o conhecimento organizacional. Trata-se de uma forma de gerir o recurso conhecimento, essencial para garantir a competitividade da organização (TERRA, 2000). A Gestão do Conhecimento envolve diversos processos de compartilhamento de experiências, vivências e lições aprendidas, assim como a captura, a filtragem, a validação, o compartilhamento e a reutilização de informações na organização (LESEURE; BROOKES, 2004).

Por fim, a Aprendizagem Organizacional, produto da Educação Corporativa, pode ser considerada como uma das principais formas de atingir os objetivos estratégicos da empresa e surge como uma resposta às constantes transformações do mercado (BITENCOURT, 2005). Tratase de um processo dinâmico, que não ocorre pontualmente e que está presente nos indivíduos, os quais aprendem, criam, adquirem e compartilham o conhecimento, o que os torna agentes capazes de aprimorar o desempenho da organização (CROSSAN; LANE; WHITE, 1999); SONG, 2008; REBELO; GOMES, 2008; TAHIR et al., 2011).

\section{ESTRATÉGIAS DE EDUCAÇÃO CORPORATIVA}

As estratégias de Educação Corporativa estão atreladas a uma cultura de aprendizagem, que inclui atividades de capacitação formais e informais visando estimular o indivíduo a criar e a compartilhar conhecimento. A ideia central é estimular a interação do profissional no seu meio físico e social, no local em que nascem os novos conhecimentos originados das necessidades práticas do cotidiano e da criatividade humana (MEISTER, 1999; PACHECO et al., 2009).

Para mobilizar e comprometer as pessoas com as estratégias de Educação Corporativa, 
é preciso (MEISTER, 1999): (1) oferecer ambiente adequado à aprendizagem; (2) considerar a Educação Corporativa como um processo e não como um espaço físico destinado a treinamentos; (3) trabalhar conceitos como cidadania corporativa, estrutura conceitual e competências básicas; (4) incluir nos programas clientes, fornecedores, parceiros e terceiros; (5) disponibilizar vários formatos de ensino; (6) incentivar a participação dos líderes; (7) apoiar os programas; (8) assumir um foco global; (9) ter um sistema claro de avaliação dos resultados; e (10) tornar a Educação Corporativa uma possível fonte de vantagem competitiva para a organização.

Com base nesses objetivos, é possível definir as principais estratégias de Educação Corporativa, cuja síntese é apresentada no Quadro 1, a seguir, elaborado a partir da revisão da literatura.

Quadro 1 - Estratégias de Educação Corporativa

\begin{tabular}{|c|c|c|c|}
\hline Estratégias & Definição & Como ocorre & Referências \\
\hline Autoinstrução & $\begin{array}{l}\text { Aprendizagem autodirigida. } \\
\text { O indivíduo, por meio de sua } \\
\text { maturidade, busca o conheci- } \\
\text { mento necessário para o seu } \\
\text { desenvolvimento. }\end{array}$ & $\begin{array}{l}\text { O indivíduo recebe conteúdos } \\
\text { e materiais impressos ou ele- } \\
\text { trônicos para estudar onde e } \\
\text { como for mais adequado. }\end{array}$ & $\begin{array}{l}\text { Fulmer e Gibbs (1998) } \\
\text { Olaniyan (2008) } \\
\text { Pacheco et al. (2009) } \\
\text { Antonello et al. (2011) } \\
\text { Sokolova (2011) } \\
\end{array}$ \\
\hline $\begin{array}{l}\text { Aulas expositi- } \\
\text { vas }\end{array}$ & $\begin{array}{l}\text { Estratégia mais tradicional, } \\
\text { em que os indivíduos apren- } \\
\text { dem em sala aula, em conta- } \\
\text { to com um instrutor ou pro- } \\
\text { fessor. }\end{array}$ & $\begin{array}{l}\text { Representa uma educação } \\
\text { formal, em que há uma pro- } \\
\text { gramação e um conteúdo de- } \\
\text { finido que deve ser trabalha- } \\
\text { do com os aprendizes. }\end{array}$ & $\begin{array}{l}\text { Olaniyan (2008) } \\
\text { Pacheco et al. (2009) } \\
\text { Antonello et al. (2011) }\end{array}$ \\
\hline Debates & $\begin{array}{l}\text { Tipo de estratégia que permi- } \\
\text { te a discussão e a reflexão em } \\
\text { conjunto com facilitadores, } \\
\text { professores ou outros parti- } \\
\text { cipantes. }\end{array}$ & $\begin{array}{l}\text { Seminários, congressos, sim- } \\
\text { pósios e discussão de leituras. } \\
\text { Por meio do diálogo e do con- } \\
\text { vívio, é possível absorver e in- } \\
\text { terpretar o conhecimento. }\end{array}$ & $\begin{array}{l}\text { Pacheco et al. (2009) } \\
\text { Antonello et al. (2011) }\end{array}$ \\
\hline $\begin{array}{l}\text { Aprendizagem } \\
\text { baseada em } \\
\text { problemas }\end{array}$ & $\begin{array}{l}\text { Envolve a resolução de pro- } \\
\text { blemas identificados no con- } \\
\text { texto dos próprios aprendi- } \\
\text { zes, relacionados às suas ati- } \\
\text { vidades na organização. }\end{array}$ & $\begin{array}{l}\text { A partir da identificação do } \\
\text { problema central, busca-se } \\
\text { compreender suas causas } \\
\text { e seus efeitos e identificar } \\
\text { meios para a sua resolução, } \\
\text { com base em diversas fontes } \\
\text { de informação. }\end{array}$ & $\begin{array}{l}\text { Olaniyan (2008) } \\
\text { Pacheco et al. (2009) } \\
\text { Antonello et al. (2011) } \\
\text { Saccol, Schlemmer e } \\
\text { Barbosa (2010) }\end{array}$ \\
\hline Estudo de caso & $\begin{array}{l}\text { Refere-se à análise de fatos } \\
\text { reais e à proposta de soluções } \\
\text { aos problemas apresentados. } \\
\text { Esse conhecimento deve ser } \\
\text { absorvido pelo máximo de } \\
\text { pessoas que estão envolvidas } \\
\text { em processos semelhantes. }\end{array}$ & $\begin{array}{l}\text { Pressupõe a análise de casos } \\
\text { práticos de dentro ou de fora } \\
\text { da empresa. É uma prática } \\
\text { que pode ocorrer em grupo } \\
\text { ou de forma individual. }\end{array}$ & $\begin{array}{l}\text { Pacheco et al. (2009) } \\
\text { Antonello et al. (2011) }\end{array}$ \\
\hline Dramatização & $\begin{array}{l}\text { Representação de uma deter- } \\
\text { minada situação ou fato, ge- } \\
\text { rando reflexão sobre algum } \\
\text { processo que pode ser vincu- } \\
\text { lado à organização. }\end{array}$ & $\begin{array}{l}\text { Representação de situações } \\
\text { reais (drama). }\end{array}$ & Pacheco et al. (2009) \\
\hline $\begin{array}{l}\text { Workshops ou } \\
\text { oficinas de tra- } \\
\text { balho }\end{array}$ & $\begin{array}{l}\text { Envolve sessões de aprendi- } \\
\text { zagem prática, por meio de } \\
\text { ações e geração de produtos } \\
\text { concretos ao final das ativi- } \\
\text { dades. }\end{array}$ & $\begin{array}{l}\text { Evento conduzido por uma ou } \\
\text { mais pessoas, com o objetivo } \\
\text { de unir teoria e prática. É uma } \\
\text { forma de materializar o conheci- } \\
\text { mento gerado entre os indivídu- } \\
\text { os. Há sempre um trabalho prá- } \\
\text { tico e um "produto" da oficina. }\end{array}$ & $\begin{array}{l}\text { Pacheco et al. (2009) } \\
\text { Antonello et al. (2011) }\end{array}$ \\
\hline Benchmarking & $\begin{array}{l}\text { Visa à observação de práticas } \\
\text { de outras organizações, com } \\
\text { o objetivo de aprendizado e } \\
\text { adequação às necessidades } \\
\text { da organização. }\end{array}$ & $\begin{array}{l}\text { Para aplicação dessa estraté- } \\
\text { gia, é preciso ter um diagnós- } \\
\text { tico interno e um roteiro com } \\
\text { os itens que devem ser obser- } \\
\text { vados. }\end{array}$ & $\begin{array}{l}\text { Fulmer e Gibbs (1998) } \\
\text { Pacheco et al. (2009) }\end{array}$ \\
\hline
\end{tabular}




\begin{tabular}{|c|c|c|c|}
\hline Estratégias & Definição & Como ocorre & Referências \\
\hline Job rotation & $\begin{array}{l}\text { É uma prática que permite } \\
\text { aos indivíduos exercerem ati- } \\
\text { vidades diferentes dentro da } \\
\text { organização, adquirindo uma } \\
\text { visão sistêmica dos proces- } \\
\text { sos. }\end{array}$ & $\begin{array}{l}\text { O indivíduo é retirado de sua } \\
\text { rotina de trabalho e conhece } \\
\text { outros ambientes, exercendo } \\
\text { diferentes atividades, o que } \\
\text { estimula a prática e a reflexão } \\
\text { sobre a prática. }\end{array}$ & $\begin{array}{l}\text { Rebelo e Gomes (2008) } \\
\text { Olaniyan (2008) } \\
\text { Pacheco et al. (2009) } \\
\text { Antonello et al. (2011) }\end{array}$ \\
\hline $\begin{array}{l}\text { Participação } \\
\text { em projetos }\end{array}$ & $\begin{array}{l}\text { Trata-se de um aprendizado } \\
\text { vivenciado na prática, em } \\
\text { que o profissional tem uma } \\
\text { meta específica a ser atingida } \\
\text { no final do projeto. }\end{array}$ & $\begin{array}{l}\text { O indivíduo pode contar com } \\
\text { um ou mais profissionais para } \\
\text { orientá-lo na condução das } \\
\text { atividades, proporcionando } \\
\text { feedbacks constantes quanto } \\
\text { ao seu desempenho. }\end{array}$ & $\begin{array}{l}\text { Pacheco et al. (2009) } \\
\text { Tahir et al. (2011) }\end{array}$ \\
\hline Jogos & $\begin{array}{l}\text { Envolvem atividades lúdicas } \\
\text { que podem ser tanto compe- } \\
\text { titivas quanto colaborativas. }\end{array}$ & $\begin{array}{l}\text { Jogos pressupõem a existên- } \\
\text { cia de atividades que envol- } \\
\text { vam ações, com regras e obje- } \\
\text { tivos claros a serem atingidos, } \\
\text { assim como recompensas } \\
\text { pelo sucesso obtido. }\end{array}$ & $\begin{array}{l}\text { Pacheco et al. (2009) } \\
\text { Arcanjo, Carvalho e Viei- } \\
\text { ra (2009) }\end{array}$ \\
\hline $\begin{array}{l}\text { Comunidades } \\
\text { de Prática }\end{array}$ & $\begin{array}{l}\text { São grupos de pessoas que } \\
\text { compartilham interesses e } \\
\text { conhecimentos comuns por } \\
\text { algo que praticam. }\end{array}$ & $\begin{array}{l}\text { As pessoas compartilham suas } \\
\text { experiências (de forma pre- } \\
\text { sencial ou em meio digital), } \\
\text { por meio da narração de suas } \\
\text { vivências prévias, colaboran- } \\
\text { do na resolução de proble- } \\
\text { mas. }\end{array}$ & $\begin{array}{l}\text { Brown e Duguid (1991) } \\
\text { Pacheco et al. (2009) } \\
\text { Antonello et al. (2011) } \\
\text { Wenger et al. (2009) }\end{array}$ \\
\hline $\begin{array}{l}\text { Coaching } \\
\text { Mentoring }\end{array}$ & $\begin{array}{l}\text { Envolve o acompanhamento } \\
\text { do indivíduo por um profis- } \\
\text { sional, em que o foco é o de- } \\
\text { senvolvimento por meio de } \\
\text { diálogos que o incentivem a } \\
\text { pensar em suas ações e em } \\
\text { seu desenvolvimento. }\end{array}$ & $\begin{array}{l}\text { Pode ser conduzido por exe- } \\
\text { cutivos, consultores externos } \\
\text { e internos. }\end{array}$ & $\begin{array}{l}\text { Olaniyan (2008) } \\
\text { Pacheco et al. (2009) }\end{array}$ \\
\hline
\end{tabular}

Fonte: elaborado pelos autores

É importante ressaltar que o Quadro 1 destaca algumas das principais estratégias de Educação Corporativa de forma não exaustiva, já que podem haver outras práticas específicas de empresas ou setores. Além disso, o enfoque nesse Quadro são as ações de capacitação e de desenvolvimento (existindo diversas outras ações de Educação Corporativa relacionadas, por exemplo, à Gestão por Competências e à Gestão do Conhecimento).

Conforme demonstra o Quadro 1, as estratégias de ensino e de aprendizagem a serem utilizadas nas atividades de Educação Corporativa podem tanto visar a uma aprendizagem individualizada quanto promover o desenvolvimento da colaboração e da cooperação entre as pessoas, dependendo da concepção epistemológica e da abordagem pedagógica adotada. Uma concepção epistemológica nada mais é do que uma crença sobre como nós, humanos, conhecemos nossa realidade, relacionando-se, assim, com a nossa concepção sobre o modo como aprendemos. Essa concepção epistemológica irá definir as práticas didático-pedagógicas desenvolvidas durante os processos de capacitação (BECKER, 1997, 2001). Pode-se, por exemplo, adotar práticas pedagógicas mais diretivas (centradas no professor ou instrutor) ou práticas pedagógicas mais interacionistas (centradas na interação entre alunos e professores/instrutores e outros aprendizes).

A partir da análise da literatura, percebe-se que, se o objetivo é o desenvolvimento de competências, é fundamental que as atividades de Educação Corporativa permitam a ação, e não o mero acúmulo de conteúdo. Conforme Perrenoud (1999), exemplos não bastam para a criação de competências, sendo preciso propor um problema e permitir aos aprendizes agir e refletir sobre ele. 
Isso não significa que outras abordagens mais "tradicionais", como a apresentação de conceitos, de aulas expositivas e de palestras, não possam ser utilizadas nas atividades de Educação Corporativa. Elas podem ser muito interessantes, a depender do objetivo, mas são limitadas para o desenvolvimento de competências, pois muitas delas pressupõem a passividade do aprendiz, especialmente aquelas que permitem pouca interação (mera exposição).

\section{APRENDIZAGEM ORGANIZACIONAL}

Pode-se definir a Aprendizagem Organizacional como um dos principais fatores para a competitividade e sobrevivência das organizações, pois é o processo pelo qual uma organização mantém ou aprimora seu desempenho a partir da experiência de seus colaboradores, que ocorre ao mesmo tempo individual e coletivamente e está atrelada à cultura da empresa. Trata-se de um fenômeno que busca competitividade por meio de inovação em um ambiente mercadológico incerto e que tem sido um dos principais alvos de estudos por pesquisadores desde a década de 1990, quando esse assunto passou a ser enfatizado e ganhou importância (SOUZA, 2004; CROSSAN; DUTTA, 2005; REBELO; GOMES, 2008; SONG, 2008; ALAM et al., 2011).

A forma como a empresa se adapta ao ambiente e às mudanças internas e externas é uma das características da Aprendizagem Organizacional (TAHIR et al., 2011), cujo processo ocorre em três níveis: individual, grupal e organizacional. No nível individual, estão a Intuição e a Interpretação, envolvendo competência, capacidade e motivação para desempenhar tarefas. Em nível grupal, a aprendizagem ocorre por meio da Integração, no momento em que as pessoas debatem, explicam um determinado processo, dialogam e compartilham seu entendimento com colegas em diferentes perspectivas. Quando o conhecimento aprendido pelos indivíduos é disseminado, envolve feedbacks e está alinhado com registros em sistemas, procedimentos, estratégias e cultura, passa-se à Institucionalização, pois, nesse momento, o conhecimento passa a pertencer também à organização (CROSSAN; LANE; WHITE, 1999; BONTIS et al., 2002; CROSSAN; DUTTA, 2005; TAHIR et al., 2011; ALAM et al., 2011).

O Quadro 2, exposto a seguir, explica em detalhes cada um dos 4 "Is", elaborados por Crossan, Lane e White (1999), que evidenciam as diferentes formas de aprendizagem no contexto organizacional.

Quadro 2 - Processo de Aprendizagem Organizacional

\begin{tabular}{|c|c|c|c|}
\hline Nível & Processo & Definição & Entradas/Saídas \\
\hline \multirow{2}{*}{ Individual } & Intuição & $\begin{array}{l}\text { É um aprendizado individual, que envolve perceber } \\
\text { as similaridades, as diferenças, os padrões e as pos- } \\
\text { sibilidades, sendo um processo subconsciente. Utili- } \\
\text { za o conhecimento tácito, que é adquirido e utilizado } \\
\text { com base nas experiências do indivíduo. É da intui- } \\
\text { ção que nascem ideias, inovação e mudanças. }\end{array}$ & $\begin{array}{l}\text { Experiências } \\
\text { Imagens } \\
\text { Metáforas }\end{array}$ \\
\hline & Interpretação & $\begin{array}{l}\text { Parte de elementos conscientes para o processo de } \\
\text { aprendizagem do indivíduo. Permite explicar e criar } \\
\text { mapas cognitivos, transformando aquilo que era in- } \\
\text { tuição em coisas que podem ser explicadas e nome- } \\
\text { adas. }\end{array}$ & $\begin{array}{l}\text { Linguagem } \\
\text { Mapa cognitivo } \\
\text { Conversação/ } \\
\text { diálogo }\end{array}$ \\
\hline Grupo & Integração & $\begin{array}{l}\text { Trata-se de uma ação coletiva, em que se desenvol- } \\
\text { ve e compartilha entendimento entre os membros } \\
\text { de um grupo. A evolução da linguagem estende a } \\
\text { integração para a interação entre os indivíduos, por } \\
\text { meio de conversas que possibilitam o compartilha- } \\
\text { mento dos significados. }\end{array}$ & $\begin{array}{l}\text { Compartilhamento } \\
\text { de conhecimento } \\
\text { Alinhamento mútuo } \\
\text { Sistemas interativos }\end{array}$ \\
\hline
\end{tabular}




\begin{tabular}{|c|c|c|c|}
\hline Nível & Processo & Definição & Entradas/Saídas \\
\hline Organização & $\begin{array}{l}\text { Instituciona } \\
\text {-lização }\end{array}$ & $\begin{array}{l}\text { A aprendizagem organizacional só se concretiza por } \\
\text { meio da aprendizagem de seus membros. Os conhe- } \\
\text { cimentos individuais devem ser incorporados à or- } \\
\text { ganização, por meio de sistemas, rotinas, manuais, } \\
\text { registros e outras formas que permitam que outros } \\
\text { indivíduos possam ter acesso às mesmas informa- } \\
\text { ções. }\end{array}$ & $\begin{array}{l}\text { Rotinas } \\
\text { Sistemas de diagnós- } \\
\text { tico } \\
\text { Regras e procedi- } \\
\text { mentos }\end{array}$ \\
\hline
\end{tabular}

Fonte: adaptado de Crossan, Lane e White (1999, p. 525) e Crossan e Dutta (2005, p. 434)

O processo de Aprendizagem Organizacional é dinâmico e ocorre em dois sentidos: o feedforward, quando a aprendizagem ocorre do indivíduo para o coletivo, podendo ser institucionalizada na organização, seja pela formalização de normas, manuais ou sistemas; e o feedback, que está relacionado com o que foi aprendido e utilizado e com seu impacto individual e no grupo. Esses dois sentidos perpassam os 4 "Is" (CROSSAN; LANE; WHITE, 1999). A Figura 1 demonstra oframework proposto por Crossan, Lane e White (1999).

Aprendizagem Organizacional como um processo Dinâmico

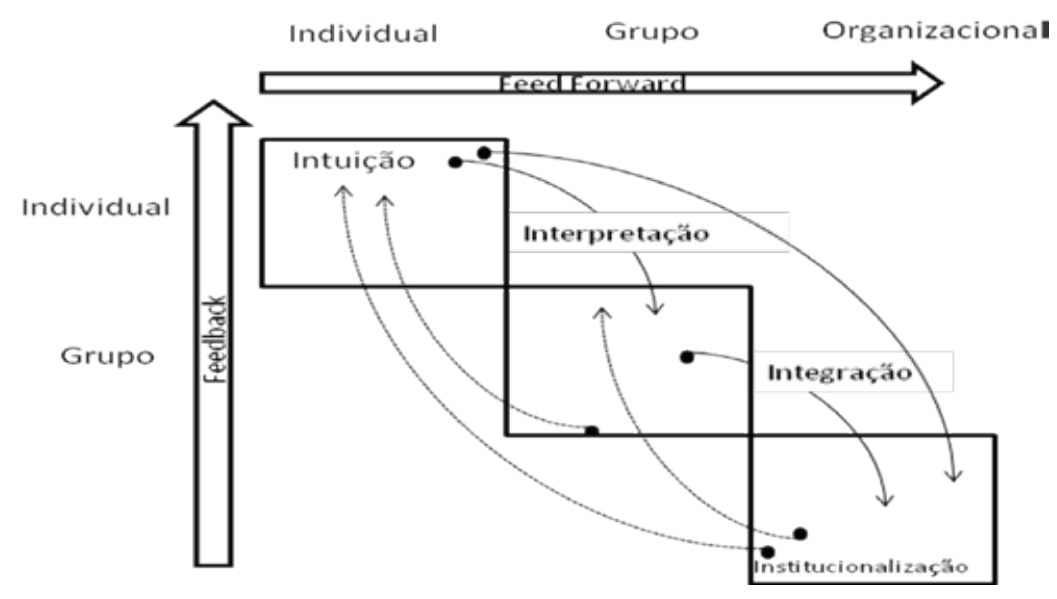

Figura 1: Aprendizagem Organizacional como processo dinâmico Fonte: Crossan, Lane e White (1999, p. 532)

\section{RELAÇÕES ENTRE AS ESTRATÉGIAS DE EDUCAÇÃO CORPORATIVA E O FRAMEWORK DE APRENDIZAGEM ORGANIZACIONAL}

A Educação Corporativa é um processo, um sistema integrado, entre Gestão do Conhecimento, Gestão por Competências e Aprendizagem Organizacional, conforme já explicado neste artigo. Esse processo é um dos facilitadores para que a Aprendizagem Organizacional ocorra de fato, transformando o conhecimento do indivíduo, até então tácito, em conhecimento explícito presente na organização (MEISTER, 1999; KROG et al., 2001; FLEURY;E OLIVEIRA, 2002; EBOLI, 2004).

A relação entre as estratégias de Educação Corporativa e o framework de Aprendizagem Organizacional é representada, a seguir, na Figura 2. 
Estratégias de Educação Corporativa e os diferentes níveis de aprendizagem organizacional

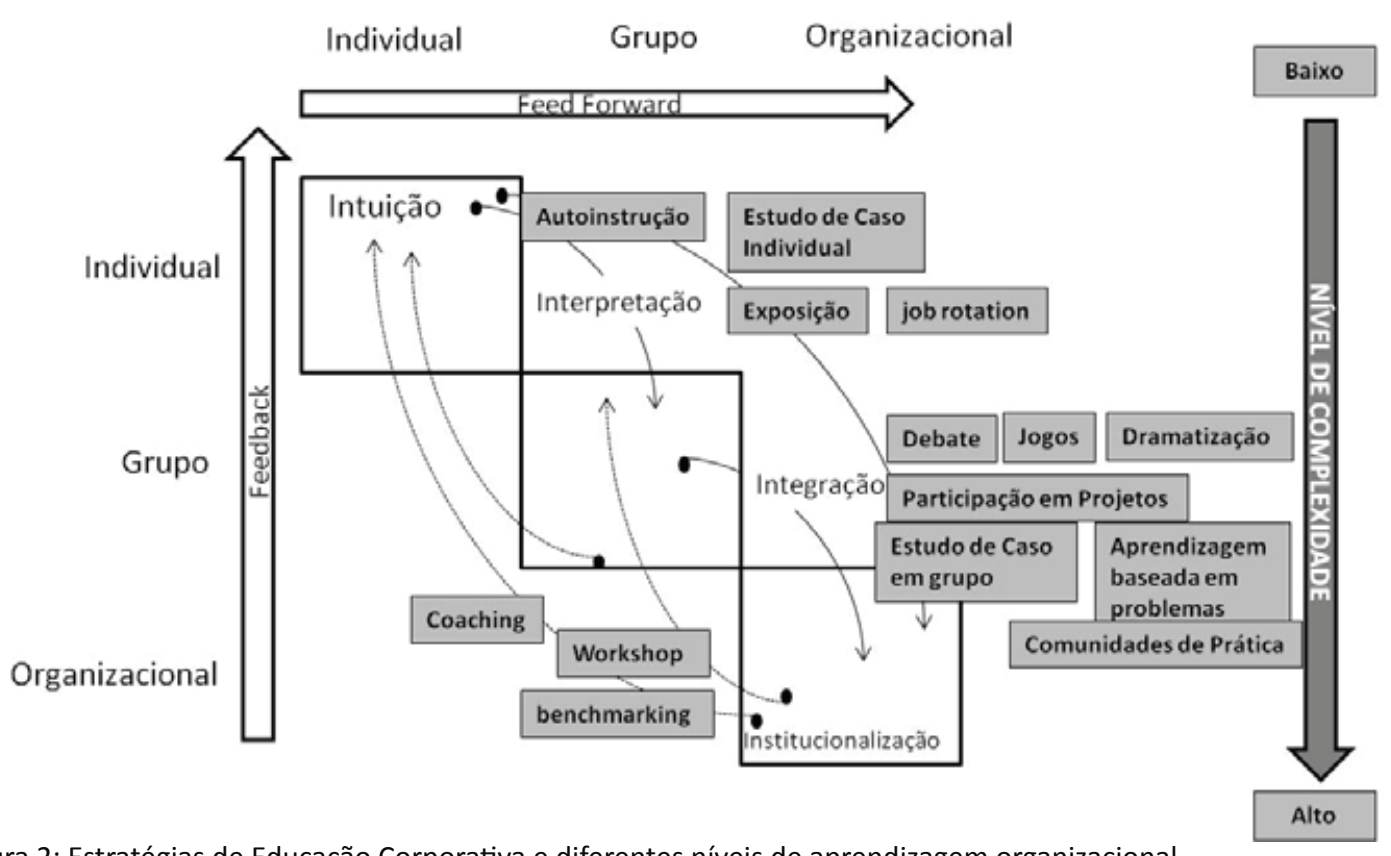

Figura 2: Estratégias de Educação Corporativa e diferentes níveis de aprendizagem organizacional. Fonte: elaborada pelas autoras, com base em Crossan, Lane e White (1999, p. 532)

Na Figura 2, é possível perceber como diferentes estratégias de Educação Corporativa (já definidas anteriormente no Quadro 1) podem ser utilizadas para promover a aprendizagem em diferentes níveis (individual, grupal ou organizacional). Em nível individual, por exemplo, ao se adotar estratégias como a autoinstrução e o estudo de caso individual, estimula-se que cada colaborador aprenda de forma independente, utilizando a sua experiência, de acordo com seu tempo e ritmo. Com estratégias mais complexas, como a exposição e principalmente o job rotation, o indivíduo poderá melhor interpretar o conhecimento adquirido, aprendendo e absorvendo como o trabalho é realizado. Este, antes teórico, ganha sentido para o indivíduo e pode ser expresso verbalmente, para ele mesmo ou para outra pessoa.

Estratégias mais simples (incluindo a exposição, tão comum em cursos e treinamentos), embora pertinentes para a aprendizagem individual, não são suficientes para promover a aprendizagem em nível de grupo. É necessário lançar mão de estratégias de Educação Corporativa mais complexas, como, por exemplo, debates, jogos e participação em projetos.

E, por fim, para promover a institucionalização (ponto forte da Aprendizagem Organizacional), são necessárias ainda outras práticas mais complexas de Educação Corporativa, como aprendizagem baseada em problemas, benchmarking, projetos, workshops, e as chamadas "comunidades de prática", nas quais as pessoas podem compartilhar conhecimento de forma sistemática, aprendendo com casos de sucesso e insucesso e criando uma "memória" sobre processos, procedimentos e formas de resolução de problemas, o que é de suma importância para a institucionalização do conhecimento.

Essas estratégias, nos três níveis, intensificam a ação, a discussão, o tratamento de problemas e a geração e o registro de lições aprendidas, o que favorece o desenvolvimento de competências, bem como o compartilhamento e a criação de conhecimentos em toda a empresa. É possível perceber que algumas estratégias de Educação Corporativa podem afetar diferentes níveis de aprendizagem, dependendo de como são conduzidas. O estudo de caso, por exemplo, se 
for aplicado individualmente, estará no primeiro nível (individual), em que o profissional aprende sozinho, ou, se for realizado em grupo, será capaz de gerar uma Integração, uma vez que juntos os membros do grupo compartilham as informações de forma interativa e aprendem. O processo de aprendizagem individual (Intuição ou Interpretação) está presente em todos os níveis, pois, ainda que a aprendizagem ocorra por meio de uma atividade em grupo, o nível individual estará sempre presente, porque é necessário que primeiro o indivíduo aprenda, para que, depois, o conhecimento possa também ser criado e compartilhado.

A seta à direita do framework proposto, na Figura 2, salienta a complexidade do processo de planejamento das estratégias de Educação Corporativa de uma organização para que a aprendizagem seja gerada em nível organizacional, e não somente individual ou de grupos isolados. Quanto mais próximo do nível Institucional, mais complexas deverão ser as estratégias para que o conhecimento deixe de pertencer somente aos indivíduos e torne-se parte da empresa, podendo gerar, a ambos, ganhos em termos de competividade, inovação e desenvolvimento.

Quando as estratégias de Educação Corporativa estão focadas no nível individual (da Intuição e Interpretação), em geral, realizam-se ações tradicionais, como aulas expositivas e autoinstrução. Analisando de forma crítica, essa é a prática adotada por boa parte das empresas quanto às suas prioridades de treinamento e desenvolvimento, o que, na verdade, não constitui o verdadeiro sentido e filosofia da Educação Corporativa (visão estratégica e integradora). O aprendizado Institucionalizado apresenta-se como o mais complexo. Ele irá demandar a utilização de estratégias de educação mais permanentes, baseadas na prática e na interação, como benchmarks, oficinas, comunidades de prática, programas de coaching e mentoring (que trabalham, além das competências individuais, o aconselhamento e o compartilhamento de visão e valores organizacionais).

O que o framework proposto salienta é que existe um processo complexo para que a Aprendizagem Organizacional se torne uma realidade na empresa, sendo necessária a utilização de práticas de Educação Corporativa também complexas, que exigem mais esforço, planejamento, tempo e investimento. Por exemplo, muitas vezes, adotam-se programas de treinamento estruturados, baseados na autoinstrução ou na exposição, por serem estes modos menos dispendiosos (dispensam ou minimizam as horas de atuação de tutores/facilitadores ou os alocam em grandes turmas). Tais estratégias podem ter um forte apelo em termos de indicadores quantitativos (muitas horas de treinamento e muitos colaboradores treinados), entretanto têm pouco potencial para colaborar com a aprendizagem em grupo e organizacional.

Também recentemente, pesquisadores têm discutido como o uso de estratégias de Educação Corporativa em diferentes modalidades de ensino (por exemplo: face-a-face, via educação a distância ou abordagem mista - blended learning) pode colaborar para diferentes níveis de aprendizagem corporativa. Semmann, Amrou e Bohmann (2012) discutem, por exemplo, de que modo LMS (Learning Management Systems, ou Sistemas para Gerenciamento da Aprendizagem) podem ser utilizados na Educação Corporativa. Esses sistemas, bastante utilizados como plataforma para e-learning (educação a distância via internet), devem não só fornecer acesso a conteúdos e interação entre as pessoas na organização, mas prover serviços mais sofisticados que permitam a criação e o compartilhamento de conhecimentos, o acompanhamento de atividades e projetos aplicados no dia a dia dos trabalhadores, a interação com tutores e a criação de formas de avaliar os resultados efetivamente gerados pelas atividades de Educação Corporativa em termos de valor agregado para o negócio. Os autores apontam que mesmo os LMS que apresentam a melhor estrutura atualmente falham em suportar esses patamares mais profundos de aprendizagem. Ou seja, as estratégias de Educação Corporativa adotadas e os sistemas que dão suporte a elas precisam superar a mera visão de treinamento e transferência de conteúdos, para 
viabilizar atividades mais práticas e interativas e que possibilitem a criação e o compartilhamento de conhecimento em nível organizacional. A possível resistência dos funcionários a novas estratégias e modalidades de educação (por exemplo, via e-learning) também precisa ser levada em conta (ALBERTIN; BRAUER, 2012).

Reis, Silva e Eboli (2010) argumentam, também, que a escolha das estratégias de Educação Corporativa deve contemplar paradigmas educacionais que vão além da visão positivista e cartesiana da racionalidade técnica, que privilegia o conteúdo, a memorização e a fragmentação de conteúdos, passando a contemplar a complexidade e a inter-relação entre conhecimentos e saberes. Estes autores reforçam a importância da prática reflexiva, que é um conceito proveniente da educação de adultos que tem migrado para a Educação Corporativa. Ela baseia-se na premissa de que a experiência no ambiente organizacional é potencialmente uma das principais formas de aprendizado e que ela deve ser acompanhada do exercício da reflexão para maximizar a aprendizagem. Isso corrobora a indicação de estratégias mais sofisticadas de Educação Corporativa para promover a aprendizagem efetiva em nível organizacional.

Entretanto, uma abordagem vivencial-reflexiva não pode se limitar ao nível individual e, mesmo nesse nível, requer algum tipo de interação interpessoal para ocorrer. Por isso, as estratégias de Educação Corporativa devem privilegiar práticas que potencializam a reflexão e que demandam algum tipo de interação, como compartilhar experiências e conhecimentos, solicitar feedback, aprender com os erros, praticar o storytelling e o coaching e fomentar comunidades de prática (REIS; SILVA; EBOLI, 2010).

É importante também adotar metodologias para avaliar os resultados das estratégias de Educação Corporativa adotadas, embora esse seja um trabalho complexo pela dificuldade de medir o retorno quantitativo e qualitativo dessas iniciativas, como discutem recentemente Tumelero et al. (2012).

\section{CONSIDERAÇÕES FINAIS}

As estratégias de Educação Corporativa representam processos pelos quais a Aprendizagem Organizacional pode ocorrer na prática, considerando cada um dos níveis propostos por Crossan, Lane e White (1999). Diante disso, propôs-se neste artigo um framework que possibilita retratar como essas estratégias contribuem para a Aprendizagem Organizacional e como podem ser atreladas a cada um dos níveis de aprendizagem, além de ressaltar a complexidade existente em cada uma dessas estratégias (sua contribuição de ordem teórica).

Como contribuição de ordem prática, o framework proposto enfatiza que, para que a empresa como um todo e, mais especificamente, para que a área de Gestão de Pessoas promovam a Aprendizagem Organizacional, é preciso utilizar estratégias de Educação Corporativa mais complexas, pois as práticas tradicionais reforçam em geral o aprendizado em nível individual (Intuição e Interpretação), com pouco impacto em outras formas mais profundas de Aprendizagem Organizacional, como a Integração e a Institucionalização.

Portanto, recomenda-se o framework proposto como uma ferramenta prática, que sintetiza as relações entre as diferentes estratégias de Educação Corporativa que podem ser adotadas por uma organização e os diferentes níveis de aprendizagem que elas são, de fato, capazes de fomentar.

Uma combinação das estratégias indicadas pelo framework deve ser desenhada conforme forem os objetivos da Educação Corporativa de cada organização. Ao pensar de forma mais profunda sobre o potencial de cada estratégia, as empresas podem tomar decisões melhores sobre como investir seus recursos no desenvolvimento de seus funcionários, a fim de gerar resultados mais 
efetivos em termos de Aprendizagem Organizacional e retornos concretos para a própria empresa.

A utilização de estratégias de Educação Corporativa mais complexas, que envolvam, por exemplo, projetos e resolução de problemas reais, poderá gerar melhoria nos processos organizacionais, bem como propostas de novos produtos e serviços. Com isso, quando corretamente aplicadas, essas estratégias possuem não só alto impacto para a aprendizagem, mas também potencial de gerar resultados práticos tanto para os indivíduos quanto para os negócios.

A título de ilustração, uma melhoria de processo empresarial gerada por meio de um projeto de aprendizagem grupal, baseado em problemas reais, poderá possibilitar uma redução de custos capaz de superar o valor investido na capacitação desse projeto. O mesmo vale para a criação de novos produtos ou serviços ou para o seu aprimoramento, o que poderá aumentar as receitas organizacionais, havendo, muitas vezes, um retorno maior que o investimento aplicado na própria capacitação.

Este artigo apresentou, assim, uma proposta de framework baseada na teoria e na reflexão sobre as práticas de Educação Corporativa na atualidade. Estudos futuros poderão aplicar o framework proposto para a análise de casos reais e também expandir as estratégias nele indicadas. Uma das limitações deste artigo é, no entanto, o fato de que as estratégias aqui consideradas não esgotam todas as possibilidades existentes para as práticas de Educação Corporativa.

\section{REFERÊNCIAS}

ALAM, M., H; KHAN, M., M; D.OST, M., K.B. Organizational Knowledge Formation Process, Organizational Learning and Human Resource Development. Interdisciplinary Journal of Contemporary Research in Business, Vol 3, no 1, p. 210-221, 2011

ALBERTIN, A. L., BRAUER, M. Resistência à educação a distância na educação corporativa. Revista de Administração Pública, vol.46, n.5, 1367-1389, 2012.

ANTONELLO, C. S; GODOY, A. S. Aprendizagem organizacional no Brasil. Porto Alegre: Bookman, 2011.

ANTONINI, L. Desafios enfrentados por pequenas e médias empresas do setor de software nos processos de educação corporativa: um estudo exploratório. Dissertação de Mestrado em Administração da Unisinos. São Leopoldo, 2009.

ARCANJO, F. S; CARVALHO, M. S; VIEIRA, F. O. (2009) O Papel dos Jogos como Recurso Didático em Programas de Educação Corporativa. Anais do XXXIII EnANPAD, São Paulo.
BARRETO, L. M. T. S.; SILVA, M. P.; FISCHER, A. L.; ALBUQUERQUE, L. G.; AMORIM, W. A. C. Temas Emergentes em Gestão de Pessoas: uma Análise da Produção Acadêmica. Revista de Administração da UFSM, v. 4, n. 2, art. 2, p. 215-232, 2011.

BECKER, F. Educação e Construção do Conhecimento. Porto Alegre: Artmed, 2001.

BECKER, F. No princípio era a ação! Ação, função simbólica e inteligência emocional. Pátio: Revista Pedagógica 1 (1). Porto Alegre: maio/jul., 1997, p. 22-24.

BITENCOURT, C. C. Gestão de competências e aprendizagem nas organizações. São Leopoldo: UNISINOS, 2005.

BITENCOURT, C., KLEIN, M. J. (2007) Desenvolvimento de competências: a percepção dos egressos do curso de graduação em administração, Anais do XXXI EnANPAD, Rio de Janeiro.

BONTIS, N.; CROSSAN, M. M; HULLAND, J. Managing an organizational learning system by aligning sotcks and flows. Jornal of Management Studies, 39:4 junho, 2002.

BROWN, J. S; DUGUID, P. Organizational learning and communities-of-pratice: toward 
a unified view of working, learning and innovation. Organization Science, vol.2, no 1, 1991.

CROSSAN, M. M; DUTTA, D. K. The nature of entrepreneurial opportunities: understanding the process using the $4 \mathrm{I}$ organizational learning framework. Entrepreneurship, theory and practice, p.425-449, 2005.

CROSSAN, M. M; LANE, H. W; WHITE, R. E. An organizational learning framework: from intuition to institution. Academy of Management Review, vol.24, nㅇ, p.522537,1999 .

EBOLI, M. Educação Corporativa no Brasil: mitos e verdades. São Paulo: Editora Gente, 2004

EBOLI, M., HOUMEAUX, F. J; CASSIMIRO, W. T. (2011) Educação Corporativa: governança, dinâmica e estrutura das universidades corporativas no Brasil, Anais do III EnGPR, João Pessoa,2011

EBOLI, M.; FISCHER, A. L; MORAES, F. C.C; AMORIM, W. A.C. Educação Corporativa: fundamentos, evolução e implantação de projetos. São Paulo: Atlas, 2010.

EBOLI, M.; O desenvolvimento das pessoas e a educação corporativa. Em: FLEURY, Maria.T. L. As pessoas da organização. São Paulo: Editora Gente, 2002.

FILMER, R. M; GIBBS, P. A. Lifelong learning at the corporate university. Carrer Development International, v.3, iss: 5, p.177-184, 1998.

FLEURY, M. T. L. A Gestão por competência e a estratégia organizacional. Em: FLEURY, M. T. L. As pessoas da organização. São Paulo: Editora Gente, 2002.

FLEURY, M. T. L.; OLIVEIRA, M. M. J. Aprendizagem e gestão do conhecimento. Em: FLEURY, M.T.L. As pessoas da organização. São Paulo: Editora Gente, 2002.
KROGH, G. V; ICHIJO, K.; NONAKA, I. Facilitando a criação de conhecimento: reinventando a empresa como poder de inovação contínua, Rio de Janeiro, Campus, 2001.

LE BOTERF, G. Desenvolvendo a competência dos profissionais. 3a. Ed. Porto Alegre: Bookman, 2003, 278 p.

LESEURE, M.; BROOKES, N. Knowledge Management benchmarks for Project management. Journal of Knowledge Management, vol. 8, no. 01, 2004.

MARINELLI, M.. Educação Corporativa: um estudo sobre modelos de avaliação de programas. Fortaleza: Editora UFC, 2007.

MARIOTTI, H. Organizações de aprendizagem: educação continuada e a empresa do futuro. São Paulo: Editora Atlas, 1999.

MEISTER, J. C. Educação corporativa: a gestão do capital intelectual através das Universidades Corporativas, São Paulo: Makron, 1999-2004.

OLANIYAN, D; OJO, L., B. Staff Training and Development: A Vital Tool for Organisational Effectiveness. European Journal of Scientific Research, Vol.24 No.3, pp.326-331, 2008.

PACHECO, L.; SCOFANO, A. C; BECKERT, M.; SOUZA, V. Capacitação e desenvolvimento de pessoas. Rio de Janeiro: Editora FGV, 2009.

PERRENOUD, P. Construir as competências desde a escola. Porto Alegre: ARTMED, 1999.

REBELO, T. M; GOMES, A. D. Organizational learning and the learning organization: reviewing evolution for prospecting the future. The learning organization, vol 15, no 4, 2008.

REIS, G. G.; SILVA, L. M. T.; SILVA, L. M. T. A prática reflexiva e suas contribuições para a educação corporativa. Revista de Gestão (REGE - USP), v. 17, n. 4, p. 403-419, 2010.

SACCOL, A.; SCHLEMMER, E. BARBOSA, J, F. $M$-learning e U-learning: novas perspectivas da aprendizagem móvel e ubíqua. São Paulo: 
Pearson Education: 2010.

SOKOLOVA, A. Using principles of logistics in coporate education. Global business and management research: an Internaciotional Journal, Vol.3 no 3\&4,p. 342-344 2011.

SONG, B. Research on organizational learning and knowledge creation. China-USA Business Review, vol.7, № 2, 2008.

SOUZA, Y. S. Organizações de aprendizagem ou aprendizagem organizacional. RAE-eletrônica, vol 3, no1, art.5,2004.

SEMMANN, M., AMROU, S., BOHMANN, T. Analysis of Learning Management Systems According to a Holistic View on Corporate Education Services. Sprouts: Working Papers on Information Systems, 12(30), 1-11, 2012. Disponível em: http://sprouts. aisnet.org/1410/1/Analysis_of_learning_ management_systems_according_to_a_ holistic_view_on_corporate_education_ services.pdf Acesso em: 31 jul 2012.

TAHIR, A.; NAEEM, H.; SARFRAZ, N.; JAVED, A.; $A L I, R$. Organization learning and employee performance. Interdisciplinary Journal of Contemporary Research in Business, vol.3, n-2, jun 2011.

TERRA, J. C.C. Gestão do conhecimento: o grande desafio empresarial: uma abordagem baseada no aprendizado e na criatividade. São Paulo: Negócio, 2000.

TUMELERO, C., AMORIM, W. A.C., VELOSO, E. e LUCAS, A. Relação entre práticas de educação corporativa e resultados financeiros de empresas que atuam no mercado brasileiro. Revista Administração em Diálogo, vol. 14, n. 2, p. 195-215, 2012.

WENGER, E.; WHITE, N.; SMITH, J. Digital Habitats: stewarding technologies for communities. Portland, OR: CPsquare, 2009. 